\title{
The potential of mobile phones for increasing public participation in local government in South Africa
}

\author{
H THINYANE, I SIEBÖRGER AND E REYNELL ${ }^{1}$
}

\begin{abstract}
This paper presents a critical discussion on the current use of technology and participation in local government. It discusses the rise in popularity of mobile devices, and how they have been used in ICT for development. The paper describes the results of a baseline study undertaken in a city within Makana Municipality in the Eastern Cape of South Africa, to empirically investigate how residents are currently using mobile phones and participating with local government around the area of service delivery. The findings illustrate the current state of mobile phone usage and capabilities, and the potential for using the mobile platform to increase participation in local government in South Africa. The paper also can be used to inform and guide project stakeholders on how best to implement m-participation strategies.
\end{abstract}

Keywords: Mobile phones, public participation, ICT4D

\section{Introduction}

Since the turn of this century, there has been much excitement surrounding the use of internet enabled mobile phones as a solution for a number of development issues [1]. As Ndlela notes:

Many studies of the development problems in Africa... and policy documents from organizations such as UNESCO, UNDP, and WTO... all pointed to the potential of ICTs in leapfrogging development in Africa, facilitating economic growth, enhancing lives and empowering citizens [2, p217].

Within the context of participation in government, questions have been posed as to whether electronic-government (e-government) systems can help increase the accountability of public governance [3].

Proponents of the use of technology for development cite a number of reasons for their use: increased penetration of mobile devices; availability of mobile internet; and the potential of technology to leapfrog over other developmental challenges.

Within Africa, there has been a dramatic rise in the use of mobile phones in the past 20 years. This rise has been shown to stem from a number of different sources. Most notably, there has been almost zero growth in fixed line infrastructure, necessitating people to look to other sources for their communication requirements [4].

$1 \quad$ Hannah Thinyane, Ingrid Siebörger, Edward Reynell are attached to the Computer Science Department, Rhodes University. Corresponding author: Hannah Thinyane; H.thinyane@ru.ac.za; Hamilton Building, Rhodes University, Prince Alfred St, Grahamstown, RSA 6139. 
Across Sub Saharan Africa, mobile penetration rates have been growing steadily. GSMA found that "by mid-2013 there were 502 million active SIM connection in the region (equivalent to a penetration rate of 61\%), a figure that has grown by $23 \%$ per annum over the last five years" [5, p10]. Within South Africa itself, reported mobile penetration rates vary, with GSMA reporting rates of 65.7\% [5], Nielsen Group reporting figures of 76\% [4] and some sources even reporting more than 1 active connection per citizen $(59,474,500$ mobile subscriptions in a population of 52.98 million equate to a rate of $112.26 \%$ [6]).

Some researchers [4] have tried to put these figures (in particular the more conservative figures) into perspective, saying that more people on the African continent have access to mobile phones than access to clean drinking water. The same study also showed that more South Africans use mobile phones than any other modern and traditional ICTs, including computers (6 million), televisions (27 million) and radios (28 million) [4].

As well as access to mobile devices, South Africa has also been ranked as fifth in the world for mobile data usage [4], ahead of countries such as the United States of America, which ranks seventh. When asked what they currently use their mobile phones for, a study by Nielsen Group found that:

SMS text messaging is practically ubiquitous among South African mobile customers, and is used by almost 4.2 times more people than e-mail. More than two-thirds (69\%) of consumers prefer sending texts to calling, in large part because it is less expensive, and 10 percent believe texting to be a faster way of communicating [4, p1].

Mobile devices have supported a number of great developments in a wide range of areas: the fishing industry in India [7]; a telemedicine network for rural clinics in Palestine [8]; online banking in Africa [9]; and micro-entrepreneurs in Rwanda [10]. These figures speak of the proliferation and acceptance of mobile phones across developing nations.

When we turn to the context of the use of mobile devices to increase citizen participation in government, we see that the devices are

\section{new platforms are opening up new possibilities and spaces "for different forms of} political discourses and networking" [2, p217].

It is important to note that ICTs are being increasingly used to shift the paradigm of political communication. There have been numerous cases recently of mobile devices being used to help gather people for protests and the like. Despite the potential of the devices, there is more required than access to a new technology. As Otieno notes, "the reality of widespread poverty, language barriers, and cost issues" are important to remember when considering the use of mobile phones [11]. Wasserman also warns that access to mobile devices does not explicitly entail increased participation:

\section{discourses around mobile phones make an interpretive leap from access figures to speculation about the impact of mobile phones on democracy and development without examining context [12, p150].}

However, there are a number of recent examples in Africa of the use of mobile phones to increase participation. Ushahidi, is such an example. Ushahidi, meaning "testimony" in Swahili, was designed to "harness the benefits of crowdsourcing information (using a large group of people to report on a story) and facilitate the sharing of information in an environment where rumours and uncertainty were dominant" [13]. This webpage was developed after the post-election violence in Kenya, when a wave of censorship of 
information in the media was felt. The Ushahidi platform has been successfully used across a number of different countries around the world. As stated by Wasserman, technologies such as Ushahidi are successful for "amplifying a brief political campaign or event but less successful in ensuring 'ongoing and higher levels of accountability"' [12, p152]. However, as also noted by Wasserman, "the surveillance of government also has to happen in between the 'ritual of elections'... through ongoing social movement and civil society campaigns" [12, p152]. This gap is where MobiSAM is situated, particularly focusing on ongoing accountability and citizen monitoring outside of electoral cycles. MobiSAM is a 3 and a half year, Ford Foundation funded research project investigating the use of mobile phones for increasing citizen participation in local government. At the time of writing this report, the project was mid-way through a pilot project where a local municipality in South Africa, Makana Municipality (located in the Eastern Cape Province), uses MobiSAM to increase citizen participation around the area of service delivery.

This paper presents a critical discussion on the current use of technology and participation in local government. It describes the results of a baseline study undertaken in a small town in South Africa, to empirically investigate how residents are currently using technology and participating with local government around the area of service delivery. It draws from these findings to propose the design of MobiSAM, a mobile phone based polling and reporting framework intended to increase citizen participation in local government.

\section{Context}

This section provides some contextual information on South Africa, and then the Makana Municipality. This is followed by some background on the MobiSAM project.

\subsection{South Africa}

With the new democratic dispensation in 1994, the state's new constitution and commitment to human rights were entrenched in its bill of rights. The South African Constitution is widely recognized as one of the most progressive in the world, as it guarantees both civil liberties and socio-economic rights [14]. The constitution gives the responsibility to government to provide housing, sanitation and basic services for all [15].

The reality is far different to what is promised in the Constitution, particularly for the country's poorest citizens. Prominent commentators have attributed this lack of delivery of basic services across the population to a lack of accountability at local government level, particularly with respect to a lack of public participation [14]. More recently Pravin Gordon, the Minister for Co-operative Governance \& Traditional Affairs noted that the main problems faced by local government in South Africa are "a communication breakdown between councils and citizens; no accountability; political interference in administrations; corruption; fraud; bad management; violent service delivery protests; factionalism; and depleted municipal capacity" [16, p1].

According to Statistics SA [17] there are three national poverty lines by which levels of poverty are measured; the food poverty line (FPL), the lower-bounded poverty line (LBPL) and the upper-bounded poverty line (UBPL). The FPL is the "level of consumption below which individuals are unable to purchase sufficient food to provide them with an adequate diet" [17]. The LBPL includes non-food items but requires that individuals sacrifice food items in order to obtain them, while the UBPL individual is able to purchase both sufficient food and non-food items. According to Statistics SA [17], the LBPL for March 2011 was 
R443 per month and the FPL for the same period was R321 per month. Furthermore, according to Stats SA, 45.5\% of South Africans in 2011 were considered poor and living in poverty [17].

In contrast to these levels of poverty, South Africa's municipal bill is amongst the most expensive in the world, with nearly $12 \%$ of GDP spent on wages for civil servants [18]. In the past four years, the growth in salaries of government employees has surpassed increases in all other state spending.

Despite the high levels of poverty $88.9 \%$ of South African households contain at least one working cellular phone [19]. Furthermore, $16.3 \%$ of South Africans have access to the Internet via their mobile phones (the largest method of Internet access by South Africans) [19]. Furthermore, Duncan found that in informal settlements, where some of the poorest of the South African population live, residents spent up to one quarter of their income buying airtime for their pay as you go (prepaid) mobile phones; this money is spent on mobile phone charges instead of food [20]. We would argue that this is an indicator of the importance of access to communication channels for the poor, while acknowledging that in order to achieve true universal access the needs and limitations of the poor also need to be considered when designing mobile applications.

\subsection{Makana Municipality}

Makana Municipality is situated in the Eastern Cape, one of South Africa's poorest provinces. The 4,375 km2 municipality is home to an estimated 80389 people or 21388 households [21]. The area experiences a high unemployment rate (63.4\%) and low levels of education (39.2\% of Makana residents have received primary level education or none at all) [21]. The result is that 55.5\% of Makana residents, in 2011, live below the poverty line [21] (defined by Statistics South Africa as earning less than R801 per month [21], which equates to the earning bracket above the UBPL). The number of South Africans in total at the same time living below the poverty line was $45.5 \%$ [17]. Efforts to alleviate poverty are hampered by a sluggish economy and there is an increasing dependency on social grants, with $45.5 \%$ of the total Makana population receiving some form of government grant in 2011 [22] (compared with approximately 29\% of the national population receiving some form of government grant in 2011 [17]). This places a significant burden on the municipality, particularly in delivering basic services. According to the Municipal Systems Act, a municipality is responsible for (amongst other things) municipal health services; municipal roads; sanitation; electricity reticulation; potable water; refuse removal, refuse dumps and solid waste disposal; child care facilities; and, local tourism [23]. Despite a R266 million budget in 2009/10 [24], only 21\% of Makana residents have access to potable water and only $35 \%$ to sanitation [25].

The municipality was ranked as the third worst performing municipality in the Eastern Cape Province in 2011, with 2,507 instances of misspending (R19.8 million ), making up 9\% of the total misspending in the province $[26,27]$. The Supreme Audit Institution (in South Africa called the Auditor-General, or AG) has repeatedly found the municipality unable to adequately account for the use of public resources. In 2011/2012, the AG could not obtain sufficient appropriate audit evidence to support over R48 million of municipal expenditure [28]. This was the fourth successive disclaimer that Makana had received [29], meaning that the Auditor-General could not obtain sufficient appropriate audit evidence for municipal 
expenditure. Consequently Makana was named in the top five of worst-run municipalities in South Africa in 2012, with massive mis-expenditure and poor leadership.

In 2012 the AG found that the municipality was in over R20 million in debt, and there was irregular, unauthorized, and wasteful expenditure of over R60 million [30]. At the end of 2012, both the Municipal Manager and Chief Financial Officer were removed from their posts and legally charged with misconduct [30]. At the end of 2013, the new Municipal Manager and the Strategic Manager in the mayor's office were suspended pending an investigation into the fraudulent acquisition of a R3 million payout. Furthermore, in 2014 a report, referred to as the Kabuso Report was released which named a number of senior municipal officials in alleged financial and management irregularities [31].

The situation in Makana Municipality is comparable to most local municipalities across South Africa, where "local government capacities are in short supply and financial sustainability is frequently in doubt. This hampers total government ability to perform traditional functions such as service delivery and regulation, collecting rates, user charges and fees" [32, p137]. This is not a problem that is unique to South Africa, but has been demonstrated on numerous occasions and across a number of different contexts. A recent cross-country, empirical evaluation found similar evidence across developing countries around the world [33].

\subsection{MobiSAM}

Three methods of m-government have been identified, namely: supplement, expand, and innovate [34]. The first method, supplement, may be defined as mobile tools which include an additional channel to supplement the way that government services are currently provided. An example of this would be in South Korea, where the e-government services have been expanded by adding wireless portals and interfaces to access existing e-services [35]. The second method, expand, help to extend the reach of traditional government services, so as to include previously underserved citizens. HealthLine, a telephonic service offering medical advice to citizens in Bangladesh, provides an example of expanding traditional e-government reach [36]. The service reduces the need to travel to clinics and waiting in health centre queues. The third and final method, innovate, are mobile tools which are used to "develop new services for service delivery and governance" [34, p88]. The MobiSAM system falls into the third category, aiming to enable innovative ways for local government to interact with and involve citizens.

MobiSAM consists of two separate yet equally important components. On the one side is the SAM methodology, which provides a way of engaging meaningfully with governments' service delivery processes. The second component is the proposed mobile polling application that allows municipalities to collect, collate, and visualize information [37].

Developed by the Centre for Social Accountability at Rhodes University, the Social Accountability Monitoring (SAM) methodology is a "rights-based and evidence-based framework for understanding and participating in government service delivery processes" [37, p174]. SAM is a rigorous methodology that tracks the phases of the municipal financial cycle: planning and allocation of resources, expenditure and implementation; accountability to oversight.

The proposed MobiSAM application will be a framework that allows questions to be posed by the municipality, and to be made available to registered users who can answer them either 
on their mobile phone or a desktop computer. Furthermore, we intend for residents to be able to report problems with service delivery using any one of the following: SMS; native mobile applications; mobi-site for use in mobile internet browser; and Facebook. To this end, we proposed and undertook a baseline study within the Makana municipality to better understand how many residents have access to mobile phones, how they currently use those mobile phones and how they currently interact (if at all) with the local municipality.

It is intended that media practitioners be included in MobiSAM as key partners in the process. The media are believed to play a key role in increasing participation and dialogue between a municipality and its citizens as they provide a space for the dialogue to be held, and can follow up on issues stemming from the data generated through the use of the MobiSAM framework.

\section{Research design}

In this section we discuss the research design of the baseline study undertaken in Makana Municipality, focusing on the study participants (section 3.1), the survey tools (section 3.2) employed and our methods and analysis (section 3.3).

\subsection{Participants}

Grahamstown is the largest city within the borders of the Makana Municipality, and the site from which this baseline study was conducted. Grahamstown citizens represent a microcosm of life in South Africa. According to the 2011 census results for Grahamstown, of the more than 50000 citizens, $72.78 \%$ described themselves as "Black African", 14.29\% as "Coloured", $11.22 \%$ as "White" and $0.94 \%$ as "Indian/Asian" [38]. While the split in terms of gender in the city is $52.61 \%$ female and $47.39 \%$ male [38]. The results for entire of South Africa in the same census were, 79.2\% South African residents described themselves as "Black African", 8.9\% as "Coloured", $8.9 \%$ as "White" and 2.5\% as "Indian/Asian" [19]. Nationally, gender results are female 51.7\% and male 48.2\% [39]. Despite the validity of the 2011 Census results being called into question [40,41], it was decided to try and match the race and gender demographics of the 2011 Census as closely as possible in our baseline study. As such we used Stratified sampling with simple random sampling within each strata (race and gender demographics), in order to obtain as representative a sample as possible. In order to achieve this participation was solicited in public areas across Grahamstown. One hundred and five $(n=105)$ Grahamstown citizens took part in our baseline study.

Of our sample group, $73.33 \%$ described themselves as "Black African", $10.48 \%$ as "Coloured", 12.38 as "White" and $3.81 \%$ as "Indian/Asian". Participants in the study were limited to those 18 years and older and fell into the age groups reflected in Table 1 . Of the participants, $51.43 \% \%$ were Female and $48.54 \%$ were Male.

Table 1: Age groups and percentage of participants that fell into each group

\begin{tabular}{|l|l|}
\hline Age Group & Percentage \\
\hline $18-30$ years old & $40 \%$ \\
\hline $31-45$ years old & $26.67 \%$ \\
\hline $46-60$ years old & $28.57 \%$ \\
\hline Over 60 years old & $4.76 \%$ \\
\hline
\end{tabular}




\subsection{Survey}

A four page questionnaire was developed, consisting of three sections: demographic information; mobile phone usage; and service delivery satisfaction and current participation. The first section consisted of nine questions which solicited information such as race, gender, education, employment status, and monthly income.

The second section consisted of sixteen questions soliciting feedback on mobile phone ownership, and current usage. These included questions about ownership or access to mobile phones, network choice, amount spent weekly on mobile airtime, and the use of applications on mobile devices.

The final section consisted of fifteen questions soliciting feedback on the way that residents feel that services are currently delivered by the municipality, as well as their current ways of participating with local government. The section also examined participants' engagement with traditional news channels (newspaper and radio). Questions pertaining to residents' current ways of participating with local government were informed by the Citizen Scorecard developed by the African Centre for Citizenship and Democracy [42].

Some questions asked as part of the questionnaire was outside of the scope of this paper so will not be described further.

\subsection{Method and analysis}

Ethics approval was sought and granted from Rhodes University for this study to be undertaken. After approval was obtained, two researchers began the process of identifying participants who were needed for the strata outlined in Section 3.1.

Participants were approached in July and August 2014 from a number of different areas in Grahamstown: communal areas in the township; common areas near the Assumption Development Centre (also in the township ${ }^{2}$ ); pedestrians walking down main roads in Grahamstown; and by referral from existing participants. Once a resident agreed to participate in the study, a consent form was signed.

The questionnaire described in Section 3.2 was completed orally, with the researcher questioning and transcribing participants' responses. In the process of piloting this questionnaire, this was found to be quicker than asking participants to complete the form themselves. Although the questionnaire was only available in English, interviews were conducted in either English or isiXhosa, as directed by the participant. This was done to ensure that written literacy levels did not interfere with the accuracy of the results obtained.

Once completed, questionnaire responses were captured electronically and analyzed using Microsoft Excel.

2 The term township in the South African context refers to, typically underdeveloped, urban area that was reserved for non-Whites during the Apartheid era. They are typically located on the outskirts of towns or cities. While non-Whites are no longer forced to live in townships, townships remain typically populated by poor, non-White South Africans. 


\section{Results}

This section describes the results of the study, with the results of the demographics section, use of technology section and current participation section described separately.

Across all results, responses are classified into the following race groups: White, Indian/Asian, Black African/Coloured. These combinations are performed for historical reasons as they refer to the classifications used in the former dispensation. Although Apartheid has long since passed, these classifications are used in order to determine the ongoing inequalities experienced in South Africa.

\subsection{Demographics}

Participants were asked about their levels of monthly income, $31.43 \%$ said they had no income, 5.71\% earned between R1-R400; 4.76\% between R401-R800; 15.24\% between R801-R1600; 11.43\% between R1601-R3200; 17.14\% between R3201-R6400; 4.76\% between R6401-R12800; 7.62\% R12801 or more; and 1.9\% were unsure of their monthly income.

In addition, we asked about their levels of education, of the 105 participants, $13.33 \%$ only had primary school; $21.9 \%$ had some high school education; $34.29 \%$ had a matric (pass from the final year in high school); $2.86 \%$ had a Technikon or College Diploma; and 27.62\% had a University education.

Employment status across our sample group also varied, $25.71 \%$ described themselves as students; $6.41 \%$ were part-time employed; $39.72 \%$ were full-time employed; $3.4 \%$ were selfemployed; $2.82 \%$ had temporary employment; $4.68 \%$ said that they were temporarily unemployed; $3.55 \%$ were retired; and lastly, $11.31 \%$ were unemployed.

The preferred language of each participant was asked, we found that $56.19 \%$ preferred isiXhosa; 39.05\% English, 2.86\% Afrikaans, 0.95\% isiZulu, and 0.95\% other. Literacy levels in the preferred language of the participants were gauged: $98.1 \%$ were able to read in their preferred language, while $97.14 \%$ were able to write in their preferred language.

\subsection{Use of technology}

From the findings derived from the survey of Grahamstown residents, we were able to answer seven key questions worth highlighting here. These were:

- "How many respondents own a mobile phone?";

- "How many respondents have access to a mobile phone?";

- "How do respondents pay for the use of their mobile phones?";

- "What is the average expenditure on mobile phones per earning bracket?";

- "Which do respondents value more, SMS, Data or Voice?";

- "Which online data services do they use?"; and

- "How often do respondents make use of the online data services?".

The answers to each of these seven questions are detailed below. 


\begin{tabular}{|l|r|r|}
\hline Brand & $\#$ & Percent \\
\hline Nokia & 35 & $36.84 \%$ \\
\hline Samsung & 25 & $26.32 \%$ \\
\hline BlackBerry & 11 & $11.58 \%$ \\
\hline LG & 6 & $6.32 \%$ \\
\hline Apple & 5 & $5.26 \%$ \\
\hline
\end{tabular}

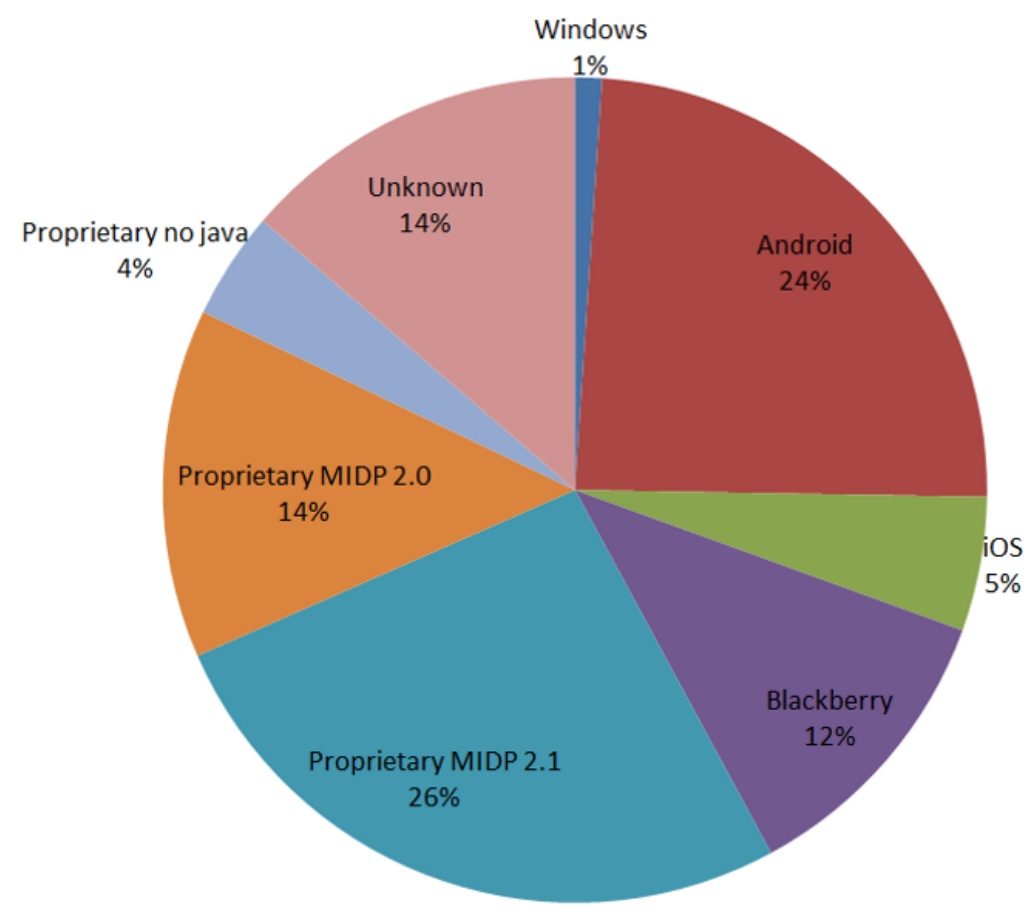

Figure 1: (a) Top five brands of mobile devices and (b) mobile operating system

Of the 105 respondents, $95.24 \%$ have access to a mobile phone $-90.48 \%$ own their own phones, while $4.76 \%$ have access to a shared mobile phone. This means that in our study, only $4.76 \%$ have no access to a mobile phone. Figure 1(a) provides an overview of the brands of mobile phones that participants own, and the number and percentage ( $n=95$ respondents who owned their own phone) of each of the top five brands. The survey sought information regarding the make and model of participants' mobile phones, so that researchers could determine the mobile operating system, as well as to determine other technical specifications of the devices ${ }^{3}$.

In some cases even though exact make and models were captured, no specific operating system was specified online for handsets. In other cases the phone operating system was simply referred to as "proprietary". In these cases, the results were grouped together, with a distinction instead made on support for Java: no Java support; MIDP 2.0; and MIDP 2.1.

As can be seen in Figure 1(b) the most popular brands of operating system are Android, Blackberry, iOS, and Windows Mobile. The Nokia handsets (36.84\% of the mobile devices - see Figure 1 (a)) make up part of the following segments: Proprietary OS with Java MIDP 2.1, Proprietary OS with Java MIDP 2.0, or Proprietary OS with no Java. This split was included to obtain a better understanding of the capabilities of the wide range of Nokia devices that were prevalent in the study. Devices that are included in the "Unknown" category are those where not enough information was provided to determine the technical specification of the device. When collecting information from participants, investigators helped to determine the make and model of the device when participants were unsure of it themselves. In the case of "Unknown" being recorded, either: the device was not with the

The GSMArena website was used for most makes / models of handsets (www.gsmarena.com). In the case that the phone specifications were not available on this site, a simple google search was used.

Td, 10(3), December 2015, pp. 241-259. 
participant, and the participant was unsure of the model so only the make could be recorded; the device was with the participant but the model number could not be located.

Of the respondents, only $72(n=72)$ were able to identify both the make and model of the mobile phones they owned or had access to. Thus, we were only able to derive the phone communication capabilities from those 72 respondents. Of the identified phones, $59.72 \%$ were WiFi enabled; $91.67 \%$ were Bluetooth enabled; $23.61 \%$ had built in Near Field Communication (NFC) capabilities; $100 \%$ were capable of $2 \mathrm{G}$ communication; $56.94 \%$ of 3G communication; $13.89 \%$ of $4 \mathrm{G}$ (LTE) communication; $51.39 \%$ had GPS capabilities; $15.28 \%$ were capable of Infrared communication; $90.28 \%$ were capable of USB communication and lastly, 69.44\% had built in FM Radios (as can be seen in Figure 2).

As previously discussed, 10 of the 105 participants did not own their own phone. A further two more respondents chose not to answer the question regarding how they paid for the use of their mobile phone. As such, the total number of respondents who answered regarding the type of payment method they use with respect to their mobile phone was 93 . Of the 93 participants who answered, $83.87 \%$ indicated that they made use of the prepaid method to pay for airtime, SMS and data use on their mobile phones. The remaining $16.13 \%$ indicated that they were on mobile phone contracts as their method of paying for the voice, SMS and data services that they consume on their devices.

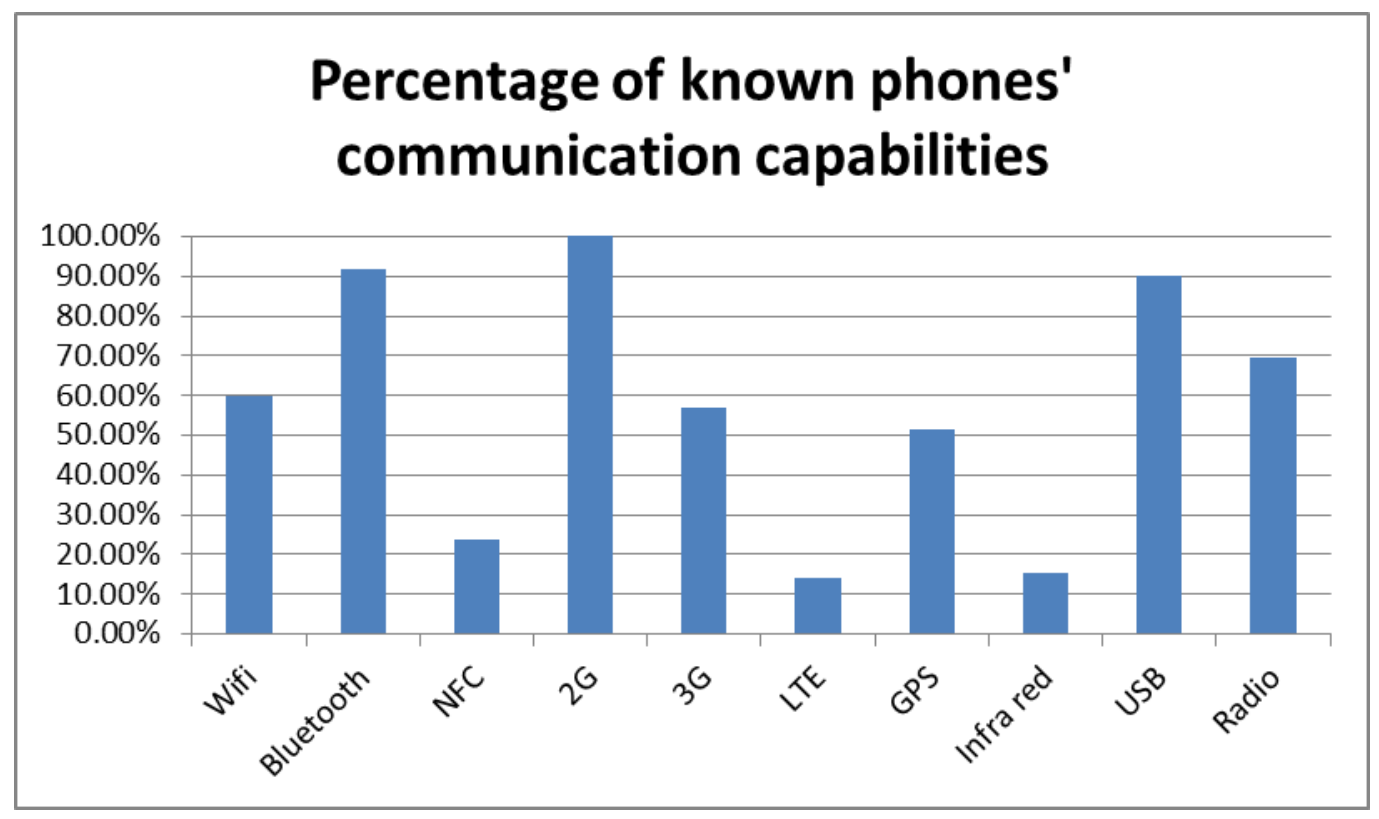

Figure 2: Communication capabilities of known mobile phones

In the survey, respondents were asked to indicate in which earning bracket they fell on a monthly basis (based on similar brackets given in the 2011 National Census). In addition, we asked them to indicate how much money they spent weekly on prepaid airtime (indicate into which bracket they fell) or on their monthly contract. We were then able to extrapolate weekly airtime expenditure over the period of a month (roughly four weeks) and correlate that to the earning bracket of each respondent. We did this by grouping the respondents together who chose the same earning brackets and then calculated the mode of expenditure for prepaid respondents and the average monetary costs of contract respondents. The results of this can be seen in Table 2. In some cases where there was no mode for the prepaid brackets per earning bracket we chose the lowest common denominator in terms of 
expenditure. Note that empty cells in the level of expenditure column for contract participants reflect that there was no one who fell into this category (rather than an expenditure of R0).

It is interesting to note that participants who rated their level of income as "no income" still had a way to purchase airtime. On closer examination of the results, $66.7 \%$ of those who said they had no income were also students, so it can be assumed that someone else was paying for their monthly mobile airtime. The remaining $33.3 \%$ described themselves as temporarily unemployed.

Table 2: Monthly income verses expenditure on mobile airtime

\begin{tabular}{|l|l|l|l|}
\hline Prepaid & $\begin{array}{l}\text { Monthly mobile } \\
\text { Lirtime }\end{array}$ & Contract \\
\hline I don't know & More than R16 & I don't know & $\begin{array}{l}\text { Monthly mobile } \\
\text { airtime }\end{array}$ \\
\hline No income & Less than R5 & No income & $\begin{array}{l}\text { R } \\
\text { 277.25 }\end{array}$ \\
\hline R1 - R400 & R5 - R15 & R1 - R400 & \\
\hline R401 - R800 & R5 - R15 & R401 - R800 & \\
\hline R801 - R1600 & R5 - R15 & R801 - R1600 & \\
\hline R1601 - R3200 & More than R30 & R1601 - R3200 & 240.00 \\
\hline R3201 - R6400 & R5 - R15 & R3201 - R6400 & \\
\hline R6401 - R12800 & R5 - R15 & R6401 - R12800 & \\
\hline R12801 or more & R16 - R30 & R12801 or more & $\begin{array}{l}\text { R } \\
487.50\end{array}$ \\
\hline
\end{tabular}

We asked participants to rank the level of importance of data, voice and SMS services offered by the mobile phone. They were ranked as most important (most), moderately important (mod) and least important (least). Answers are reflected in Table 3, where we can see that overall, data was ranked as the most important feature by each of the race groups and across male respondents. While female respondents ranked Data and Voice as equally most important. The blank space in the SMS field for Indian/Asian participants is as a result of there being no mode for the ranking of SMS amongst this demographic of participants. This was not surprising, as there were only four Indian/Asian participants who chose to take part in the study.

Table 3: Data vs SMS vs Voice

\begin{tabular}{|l|l|l|l|l|l|l|}
\hline & ALL & Female & Male & W & I/A & BA/C \\
\hline Data & Most & Most & Most & Most & Most & Most \\
\hline SMS & Mod & Mod & Least & Least & & Mod \\
\hline Voice & Mod & Most & Mod & Mod & Mod & Most \\
\hline
\end{tabular}

Participants were asked two questions about the services they use on their mobile phones. Firstly they were asked to select the messaging services that they currently use, and then 
asked to select any other services they used on their mobile phones. The results of these two questions are summarized in Table 4.

Table 4: Use of messaging service and other services

\begin{tabular}{|l|l|l|l|l|l||}
\hline & Female & Male & W & I/A & BA/C \\
\hline \hline SMS & $69 \%$ & $80 \%$ & $92 \%$ & $75 \%$ & $72 \%$ \\
\hline WhatsApp & $56 \%$ & $76 \%$ & $92 \%$ & $75 \%$ & $61 \%$ \\
\hline $\begin{array}{l}\text { BBM } \\
\text { (BlackBerry) }\end{array}$ & $2 \%$ & $16 \%$ & $8 \%$ & $50 \%$ & $7 \%$ \\
\hline Mxit & $13 \%$ & $20 \%$ & $0 \%$ & $0 \%$ & $19 \%$ \\
\hline \hline Facebook & $46 \%$ & $76 \%$ & $92 \%$ & $50 \%$ & $57 \%$ \\
\hline News & $19 \%$ & $33 \%$ & $69 \%$ & $25 \%$ & $19 \%$ \\
\hline Twitter & $13 \%$ & $29 \%$ & $38 \%$ & $25 \%$ & $18 \%$ \\
\hline E-mail & $19 \%$ & $41 \%$ & $77 \%$ & $75 \%$ & $20 \%$ \\
\hline Wikipedia & $7 \%$ & $27 \%$ & $46 \%$ & $0 \%$ & $14 \%$ \\
\hline
\end{tabular}

From Table 4 it can be seen that SMS is the most popular messaging service and Facebook (see Figure 3 (a)) as the most popular service across all gender and race groups.
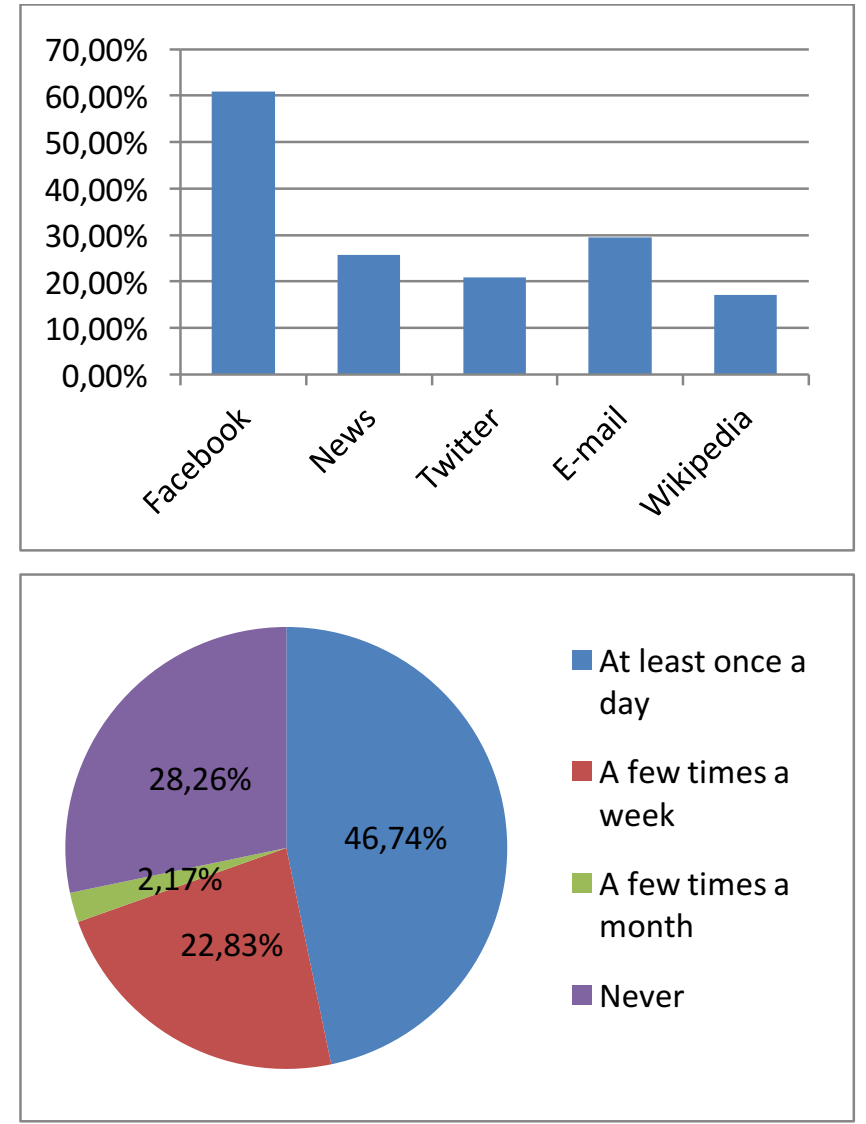

Figure 3: (a) Data services accessed by respondents; (b) Frequency of accessing online data services

Of the 105 respondents, only 92 answered the question regarding how often they made use of the above data services. From Figure 3 (b) we can see that the majority of respondents 
accessed their data services at least once per day, while a little more than a quarter never made use of any online data services.

\subsection{Current participation}

Participants were asked how they currently participate with local government in the area of service delivery. In answer to the question "have you ever made a complaint to your local municipality", $58.1 \%$ of all participants stated that they had complained (total responses for this question is $105, \mathrm{n}=61$ ). Table 5 describes the results when analyzing the ways that people chose to complain by gender and race. In the "other" category, one participant stated that he used Facebook to report a problem to the municipality.

Table 5: Methods of complaint to municipality

\begin{tabular}{|l|l|l|l|l|l|l|}
\hline & ALL & Female & Male & White & I / A & BA / C \\
\hline Petition & $25 \%$ & $23 \%$ & $27 \%$ & $80 \%$ & $0 \%$ & $20 \%$ \\
\hline Spoke to municipality & $46 \%$ & $42 \%$ & $50 \%$ & $20 \%$ & $100 \%$ & $46 \%$ \\
\hline Phoned municipality & $7 \%$ & $13 \%$ & $0 \%$ & $0 \%$ & $0 \%$ & $7 \%$ \\
\hline Ward Councillor & $20 \%$ & $19 \%$ & $20 \%$ & $0 \%$ & $0 \%$ & $22 \%$ \\
\hline Letter & $2 \%$ & $3 \%$ & $0 \%$ & $0 \%$ & $0 \%$ & $2 \%$ \\
\hline Other & $2 \%$ & $0 \%$ & $3 \%$ & $0 \%$ & $0 \%$ & $2 \%$ \\
\hline
\end{tabular}

When considering responses by gender, both female and male participants preferred to speak in person to people at the municipality. Anecdotally, this could be seen to be as a result of municipal officials seldomly answering the phone at their offices. When analyzing by race, white residents showed a preference for signing petitions, with all other residents preferring to speak to someone in person at the municipality.

Table 6: Participation in protest action

\begin{tabular}{|l|l|l|l|l|l|l|}
\hline & ALL & Female & Male & W & I/A & BA/C \\
\hline Yes & $39 \%$ & $45 \%$ & $33 \%$ & $15 \%$ & $25 \%$ & $44 \%$ \\
\hline No & $61 \%$ & $55 \%$ & $67 \%$ & $85 \%$ & $75 \%$ & $56 \%$ \\
\hline
\end{tabular}

The next question asked if residents had participated in a protest or demonstration within the last 12 months. One respondent did not answer this question $(n=104)$. As shown in Table 6, $39 \%$ of all respondents said that they had participated. When analyzing by gender, females participated more often than males. Interestingly there is a large split in participation between races, with White and Indian/Asian respondents participating on average far less than their Black African/Coloured counterparts.

Furthermore, we asked the participants whether they were satisfied or not with the basic services (electricity, water, sanitation, refuse removal, parks and recreation facilities, and roads and sidewalks) supplied by the municipality. A summary of the results can be seen in Table 7. From Table 7 it can be seen that the majority of participants were satisfied with the levels of service around electricity, refuse removal and sanitation. However, the majority of participants were not satisfied regarding the levels of service surrounding water, parks and recreational facilities and roads and sidewalks. 
Table 7: Levels of satisfaction regarding municipal services amongst participants

\begin{tabular}{|l|l|l|l|l|}
\hline Municipal service & Satisfied & Not satisfied & Unsure & No response \\
\hline Electricity & $82.86 \%$ & $17.14 \%$ & - & - \\
\hline Water & $16.19 \%$ & $83.81 \%$ & - & - \\
\hline Refuse removal & $73.33 \%$ & $26.67 \%$ & - & - \\
\hline Sanitation & $61.9 \%$ & $35.24 \%$ & $1.9 \%$ & $0.96 \%$ \\
\hline Parks and recreation facilities & $20.95 \%$ & $74.29 \%$ & $4.76 \%$ & - \\
\hline Roads and sidewalks & $21.9 \%$ & $78.1 \%$ & - & - \\
\hline
\end{tabular}

Another question asked residents how much agency they believed they had to change the system. One respondent chose not to answer this question $(n=104)$. Table 8 provides a summary of the results of this question. As illustrated in the table, over half of all participants believed they could make "some" or "a great deal" of difference to improve the situation in local government. When we consider the results by gender, males responded more negatively ("nothing") to the question, but also higher to the positive response ("a great deal").

Table 8: Perceived amount of agency to effect change

\begin{tabular}{|l|c|c|c|c|c|c|}
\hline & ALL & Female & Male & W & I/A & BA/C \\
\hline Nothing & $10 \%$ & $6 \%$ & $16 \%$ & $31 \%$ & $25 \%$ & $7 \%$ \\
\hline A small amount & $33 \%$ & $33 \%$ & $33 \%$ & $54 \%$ & $25 \%$ & $31 \%$ \\
\hline Some & $26 \%$ & $31 \%$ & $20 \%$ & $8 \%$ & $0 \%$ & $30 \%$ \\
\hline A great deal & $28 \%$ & $26 \%$ & $29 \%$ & $0 \%$ & $25 \%$ & $32 \%$ \\
\hline I don't know & $3 \%$ & $4 \%$ & $2 \%$ & $8 \%$ & $25 \%$ & $1 \%$ \\
\hline
\end{tabular}

Interestingly, white participants responded more negatively than any other race groups, with $85 \%$ of respondents saying an individual could make no change or "a small amount".

\section{Discussion}

While the Constitution of South Africa mandates that local governments provide basic services such as water, sanitation, electricity, refuse removal, etc. many of these tasks are not being fulfilled [43]. As a result, citizen response often takes the form of strike action and protest (South Africa has been called the "protest capital of the world" [44, p1] and has recorded as many as $900+$ protests in a single calendar year [45]), which do not typically result in meaningful, long lasting change [45].

In Grahamstown, results from the base line study indicate that the majority of citizens surveyed were dissatisfied with the level of service with regards to the provision of water, parks and recreational facilities and roads and sidewalks. However, only $58.1 \%$ of respondents had formally laid a complaint with the municipality; $39.05 \%$ of the 105 respondents were both dissatisfied and had never bothered to make a complaint to someone in their municipality. This is not surprising when one considers the responses from those surveyed regarding agency for change, in which $43 \%$ of respondents believed that they had little or no agency with which to effect change. However, local governments have been structured in such a way as to increase meaningful citizen participation by "placing more power and resources at a closer and more easily-influenced level of government" [32, p136]. The key to successful public involvement is to ensure the "meaningful, informed, and 
effective participation" of citizens in government processes [37, p170]. It is important to note thought that adequate mechanisms and skills are required in order to hold service providers accountable for their performance (or lack thereof). This is where the SAM methodology (see section 0) assists; it is a mechanism that has been used to hold service providers accountable for their performance in many Southern African Development Community (SADC) countries [37]. That said, in its current form, the SAM methodology is conducted via the post-hoc, primarily desk-based analysis of government documents. We are thus proposing that this process may be further enhanced through real-time feedback from the public, via their mobile phones.

From the results of our survey with the Grahamstown community, we saw that $90 \%$ of those surveyed owned their own phone, while a further $5 \%$ had access to a phone that they could make use of. This, together with data from organizations such as the Nielson Group which reports cellular phone penetration rates of 76\% [4] in South Africa, further strengthen the idea to use mobile phones to support citizens communicating with their local municipalities around service delivery.

With this in mind, the application needs to adhere to the following specifications (according to the results of the survey performed amongst the Grahamstown citizens):

- The application should be available for Android, iOS, Blackberry, Windows and Java based handsets in order to cater for at least $82 \%$ of the available handsets used by citizens.

- The application should be available in English, isiXhosa and Afrikaans, in order to cater for the preferred language of $98.1 \%$ of those surveyed.

- While data was highly ranked in terms of importance amongst the majority of people surveyed, more than a quarter of people surveyed never made use of data services and only $60 \%$ of known phones were capable of $3 \mathrm{G}$ or WiFi communication. As such, in order to facilitate communication for as many citizens as possible, the application should provide an SMS facility (in addition to the data usage) to allow citizens to report to and communicate with their local municipality.

- Considering that the majority of people surveyed earn R3200 or less per month, the application should be as conservative as possible on data usage in order to minimize expense in terms of airtime of citizens.

This "mobile-enhanced" SAM methodology will hopefully allow citizens to participate in local governance by giving them a direct means to interact with their municipality and express their needs and concerns. Dialog could take the form of citizen satisfaction surveys, social auditing, the monitoring of service delivery, and reporting service delivery faults or outages. The project could see feedback and results published in a local newspaper on a regular basis, thus providing a formal dialogue between citizens and local government.

\section{Conclusion and future work}

The MobiSAM project aims to encourage meaningful citizen participation within local government matters, through evidence-based engagement. To this end we have conducted a base line survey of 105 citizens, detailed in this paper, within the city of Grahamstown in the Makana Municipality (arguably a microcosm of life in South Africa). Findings suggest that Grahamstown and Makana Municipality, like other municipalities across South Africa, is plagued by service delivery short-comings. Furthermore, local citizens do not typically feel empowered to effect change, despite the structure of local governments in South Africa being 
such that power and resources are more closely situated to citizens such that they are able to more easily influence government.

Thus MobiSAM proposes to enhance the SAM methodology by facilitating real-time feedback from the public, via their mobile phones. To this end, we propose the development of an application that will target as many mobile handsets, local languages, and usage patterns as possible, in order to maximize penetration and take up within local communities. Thus, the future work of the project will focus on the application development and usability testing, with the aim of making it available to Makana citizens as a pilot study.

This paper also hopes to contribute to the growing body of knowledge around the use of mobile phones in developing countries, particularly with reference to endeavors to support citizen engagement with (local) government by employing evidence-based research initiatives.

\section{Acknowledgements}

Our thanks to Ford Foundation for the generous funding that has supported this research. Thanks also goes to Debbie Coulson for helping to develop the baseline study questions on service delivery satisfaction and current participation.

\section{References}

[1] M. Fernández-Ardèvol, "Mobile communication and socio-economic development: A latin american perspective," United Nations, Tech. Rep., 2010. [Online]. Available: http://www.un.org/wcm/content/site/chronicle/home/archive/issues2011/thedigitaldividend/mobilecommunicationandsocioeconomicdevelopment

[2] M. Ndela, The Power of Communication: Changes and challenges in African Media, ser. The Power of Communication: Changes and challenges in African Media. Oslo: Oslo Academic Press, 2009, ch. New ICTs and Social Change in Southern Africa.

[3] H. Düke, Performance Accountability and Combating Corruption, ser. Performance Accountability and Combating Corruption. Washington DC: World Bank, 2007, ch. Can e-government make public governance more accountable?

[4] J. Hutton, "Mobile phones dominate in south africa," Nielson Group, Tech. Rep., 2011. [Online]. Available: http://blog.nielsen.com/nielsenwire/global/mobilephones-dominate-in-south-africa/

[5] GSMA, "Sub-saharan africa mobile economy 2013," GSMA, Tech. Rep., 2014. [Online]. Available: http://www.gsmamobileeconomyafrica.com/SubSaharan\%20Africa_ME_Report_English_2013.pdf

[6] _ - "African mobile observatory: Driving economic and social development through mobile services," GSMA, Tech. Rep., 2012. [Online]. Available: http://www.gsma.com/spectrum/wp-content/uploads/2011/12/Africa-Mobile-Observatory2011.pdf

[7] A. Reuben, "Mobile phones and economic development: Evidence from the fishing industry in india," in Information and Communication Technologies and Development, 2006. ICTD '06. International Conference on, 2006, pp. 48-56.

[8] D. I. Zatari, "Development of a wireless rural telemedicine network and management system," International Journal of Networking and Virtual Organisations, vol. 4, pp. 109$117,2007$. 
[9] B. Dybwad, "Cellphone proliferation in africa creates basis for low-cost mobile banking," Online report, 2005, last Accessed: March 2007. [Online]. Available: http://www.engadget.com/2005/08/29/cellphone-proliferation-in-africa-createsbasis-for-low-cost/

[10] J. Donner, "Microentrepreneurs and mobiles: An exploration of the uses of mobile phones by small business owners in rwanda," Information Technologies and International Development, vol. 2, pp. 1-21, 2004.

[11] C. Otieno, Doing Digital Media in Africa: Prospects, promises and problems, ser. Doing Digital Media in Africa: Prospects, promises and problems. Port Elizabeth, South Africa: Konrad Adenauer Stiftung, 2009, ch. Mobile media for Africa.

[12] H. Wasserman, "Mobile phones, popular media, and everyday african democracy: Transmissions and transgressions," Popular Communication: The International Journal of Media and Culture, vol. 9, pp. 146-158, 2011.

[13] O. Okolloh, "Ushahidi, or 'testimony': Web 2.0 tools for crowdsourcing crisis information," Participatory Learning and Action, vol. 59, pp. 65-70, 2009.

[14] P. Heller, "Democratic deepening in india and south africa," Journal of Asian and African Studies, vol. 44, pp. 123-149, 2009.

[15] "Government of South Africa", "Constitution of the republic of south africa," 1996. [Online]. Available: http://www.info.gov.za/documents/constitution/1996/index.htm

[16] T. Lund, "Local government reform: Pravin's big challenge," Finacial Mail, cover story, December 2014. [Online]. Available: http://www.financialmail.co.za/coverstory/2014/12/11/local-government-reform-pravins-big-challenge

[17] "Statistics SA", "Poverty trends in south africa: An examination of absolute poverty between 2006 and 2011," Statistics SA, Tech. Rep., 2012. [Online]. Available: http://beta2.statssa.gov.za/publications/Report-03-10-06/Report-03-1006March2014.pdf

[18] J. van der Merwe, "What civil servants cost you," Online newspaper, City Press, November 2012. [Online]. Available: http://www.citypress.co.za/SouthAfrica/News/What-civil-servants-cost-you-20121103

[19] "Statistics SA", “Census 2011 key results," Statistics SA, Tech. Rep., 2012. [Online]. Available: http://www.statssa.gov.za/census/census_2011/census_products/Census_2011_Key_results.pdf

[20] J. Duncan, "The uses and abuses of political economy: the anc's media policy," Transformation, vol. 70, pp. 1-30, 2009.

[21] "Makana Municipality", "Makana municipality integrated development plan 20142015," Makana Municipality, Tech. Rep., 2014. [Online]. Available: http://www.makana.gov.za/wp-content/uploads/2013/06/IDP-FINAL-2014-15.pdf

[22] — - "Draft makana municipality integrated development plan: 2015-2016," Makana Municipality, Tech. Rep., 2014. [Online]. Available: http://www.makana.gov.za/wpcontent/uploads/2013/06/Draft-IDP-Document-2015-16.pdf 
[23] "Government of South Africa", "Local government: Municipal systems act, 2000," Government Gazette, November 2000. [Online]. Available: http://www.saflii.org/za/legis/num_act/lgmsa2000384.pdf

[24] "Makana Municipality", “Annual financial statements 30 june 2010,” Makana Municipality, Tech. Rep., 2010. [Online]. Available: http://mfma.treasury.gov.za/Documents/05.\%20Annual\%20Financial\%20Statements/2009-10/02.\%20Local\%20Municipalities/EC104\%20Makana/EC104\%20Makana\%20AFS\%202009-10\%20Unaudited.pdf

[25] — - "Integrated development plan review, 2010/2011," Makana Municipality, Tech. Rep., 2011. [Online]. Available: http://www.makana.gov.za/index.php?option=com_docman\&task=cat_view\&Itemid=26\&gid=11

[26] P. Mini, "Bad leadership drains municpal coffers," Online newspaper, 2011. [Online]. Available: $\quad \mathrm{http} / / / \mathrm{www}$.grocotts.co.za/content/bad-leadership-drains-municipalcoffers-25-07-2011

[27] - "Makana municipality in a mess, says report," Online newspaper, 2011. [Online]. Available: http://www.grocotts.co.za/content/makana-municipality-messsays-report-27-01-2011

[28] A. Mngxitama-Diko, "Ghost employees rake in millions from makana," 2013. [Online]. Available: http://www.grocotts.co.za/content/ghost-employees-rakemillions-makana-11-02-2013

[29] —- "Failed audit - 'blame bosses'," 2013. [Online]. Available: http://www.grocotts.co.za/content/directors-blame-failed-audit-03-02-2013

[30] —- "Makana's shame of disclaimers," 2012. [Online]. Available: http://www.grocotts.co.za/content/news-makanas-shame-disclaimers-11-12-2014

[31] A. Mjekula and A. Mngxitama-Diko, "Mec discusses kabuso report," 2014. [Online]. Available: http://www.grocotts.co.za/content/news-mec-discusses-kabuso-report-1209-2014

[32] M. T. Mogale, "Local governance and poverty reduction in south africa (i)," Progress in Development Studies, vol. 5, pp. 135-143, 2005.

[33] P. Bardhan and D. Mookherjee, "Corruption and decentralization of infrastructure delivery in developing countries," Boston University, Institute for Economic Development, Tech. Rep., 2000. [Online]. Available: http://rrojasdatabank.info/ddinf1.pdf

[34] K. M. Goldstein, M. Minges, and P. Surya, "Making government mobile," Maximizing Mobiles, pp. 87-101, 2012.

[35] P. Rufino, "Korean city opens mobile app centre," Online article, 2011. [Online]. Available: $\quad$ http://www.futuregov.asia/articles/2011/mar/21/korean-city-opensmobile-app-centre

[36] "Center for Health Market Innovations", "Healthline," 2015, last Accessed: July 2015. [Online]. Available: http://healthmarketinnovations.org/program/healthlinebangladesh/ 
[37] H. Thinyane and D. Coulson, "Mobisam: Mobile social accountability monitoring in south africa," in Proceedings of M4D 2012, V. Kumar and J. Svensson, Eds., February 2012, pp. 170-181. [Online]. Available: http://www.researchgate.net/profile/Tesfa_Tegegne/publication/-

241880474_Is_mHealth_Viable_to_Ethiopia_an_Empirical_Study/links/00b4953b56b3022606000000.pdf\#page $=187$

[38] A. Frith, “Census 2011 - main place grahamstown," Webpage, 2012, last Accessed: July 2015. [Online]. Available: http://census2011.adrianfrith.com/place/264004

[39] "Statistics SA", "Mobile information: Gender distribution," Statistics SA, Tech. Rep., 2013. [Online]. Available: http://mobi.statssa.gov.za/census2011/Gender.html

[40] P. de Wet, "Is census 2011 accurate? still depends on who you ask," Mail and Guardian, 2012. [Online]. Available: http://mg.co.za/article/2012-11-01-is-census2011-accurate-still-depends-who-you-ask

[41] P. Berkowitz, "Census 2011: The (incomplete) (probably inaccurate) sum of us," 2012. [Online]. Available: http://www.dailymaverick.co.za/article/2012-10-31census-2011-the-incomplete-probably-inaccurate-sum-of-us/\#.VbjNkJMvBhE

[42] "African Centre for Citizenship and Democracy", "African centre for citizenship and democracy citizen scorecard," 2013, last Accessed: April 2013. [Online]. Available: http://www.accede.co.za/downloads/citizen\%20scorecard\%20DELFT\%20web.pdf

[43] R. Mathekga and I. Buccus, "The challenge of local government structures in south africa: securing community participation," Critical Dialogue: Public Participation in Review, pp. 11-17, 2007. [Online]. Available: http://www.clearcontent.co.za/storage/files/prev_Challenge_of_local_govt_structures_in_SA.pdf

[44] P. Alexander, “A massive rebellion of the poor," Mail \& Guardian, April 2012. [Online]. Available: http://mg.co.za/article/2012-04-13-a-massive-rebellion-of-thepoor[Accessed:24/01/2015

[45] S. Booysen, "With the ballot and the brick: the politics of attaining service delivery," Progress in Development Studies, vol. 7, no. 1, pp. 21-32, 2007. 